Article

\title{
Ru-Zn catalysts for selective hydrogenation of benzene using coprecipitation in low alkalinity
}

\author{
Zhengbao Wang*, Qi Zhang, Xiaofei Lu, Shuangjia Chen, Chunjie Liu \\ College of Chemical and Biological Engineering, Zhejiang University, Hangzhou 310027, Zhejiang, China
}

\section{A R T I C L E I N F O}

Article history:

Received 22 August 2014

Accepted 24 September 2014

Published 20 March 2015

\section{Keywords:}

Coprecipitation

Low alkalinity

Benzene

Selective hydrogenation

Ru-Zn catalyst

\begin{abstract}
A B S T R A C T
Several unsupported Ru-Zn catalysts were successfully prepared using the coprecipitation method under low alkaline conditions, and their catalytic performance was evaluated for the selective liquid-phase hydrogenation of benzene. The effect of the amount of $\mathrm{ZnCl}_{2}$ added to the coprecipitation solution on the physical and catalytic properties of the Ru-Zn catalysts was studied whilst keeping the amount of the $\mathrm{NaOH}$ precipitant constant. The properties of the resulting catalysts were characterized by $\mathrm{N}_{2}$ adsorption, X-ray diffraction, and temperature-programmed reduction. The effects of the stirring rate and the amount of $\mathrm{ZnSO}_{4}$ additive on the catalytic properties of the $\mathrm{Ru}$ - $\mathrm{Zn}$ catalysts were investigated using the optimal $\mathrm{Zn}$ content. The recyclability of the optimal Ru-Zn catalyst was also explored. The results revealed that the optimal $\mathrm{Zn}$ content for the Ru-Zn catalysts was 16.7 $\mathrm{wt} \%$, and the selectivity for cyclohexene could reach up to $80 \%$ (yield $>45 \%$ ) when the benzene conversion was $57 \%$ in an aqueous solution of $\mathrm{ZnSO}_{4}(0.45 \mathrm{~mol} / \mathrm{L})$ under the optimal reaction conditions (i.e., hastelloy reactor, $1200 \mathrm{r} / \mathrm{min}, 150{ }^{\circ} \mathrm{C}$ and $5 \mathrm{MPa}$ of $\mathrm{H}_{2}$ pressure). The presence of $\mathrm{ZnO}$ crystals in the Ru catalysts was found to be critical to obtaining high selectivity for cyclohexene $(>80 \%)$. The Ru-Zn catalysts prepared under the low alkaline conditions also showed good stability, which indicates that they could potentially be used for industrial application.
\end{abstract}

(C) 2015, Dalian Institute of Chemical Physics, Chinese Academy of Sciences. Published by Elsevier B.V. All rights reserved.

\section{Introduction}

Cyclohexene is an important intermediate in the fine chemicals industry, where it is used for the construction of many organic chemicals, and this compound is therefore considered to be of significant commercial importance. The production of cyclohexanol from benzene via cyclohexene is a green process, but the commercialization of this process is considered by many scientists in the fine chemicals industry to be difficult because the partial hydrogenation of benzene is thermodynamically unfavorable. Several innovative techniques, however, have been developed to allow for the efficient partial hydrogenation of benzene. Numerous studies have been conducted towards the development of new methods for the selective hydrogenation of benzene to cyclohexene, and Ru-based catalysts have been being used in the majority of these cases because they give the best yield of cyclohexene. The first reported example of the Ru-based catalyst for the hydrogenation of benzene was provided by Hartog et al. [1] in 1963. In this particular case, benzene was hydrogenated over a Ru-black catalyst in the presence of an aliphatic alcohol, but the yield of cyclohexene was reported to be as low as $2.2 \%$. The first encouraging result for this reaction was obtained by Drinkard et al. [2], who reported that a much higher yield (30\%) of cyclohexene could be achieved when benzene was hydrogenated over a $\mathrm{Ru}$-based catalyst in the presence of water, and this basic idea

\footnotetext{
*Corresponding author. Tel: +86-571-87952391; Fax:+86-571-87951227; E-mail: zbwang@zju.edu.cn This work was supported by the National Natural Science Foundation of China (U1162129). 
was subsequently developed further by several other researchers [3-30]. The effects of numerous promoters and co-catalysts on this reaction have also been studied in detail [5-8].

In 1988, Nagahara et al. [8] of Asahi-Kasei Chemical Co., Ltd reported the synthesis of an efficient catalyst composed of a $\mathrm{Ru}$-black promoted with $\mathrm{ZnO}$ that provided a high yield of cyclohexene (48\%) from benzene with a selectivity of $80 \%$. This particular process was carried out in a mechanically agitated tetraphase reactor (i.e., oil phase: benzene; aqueous phase: $\mathrm{ZnSO}_{4}$ aqueous solution; gas phase: $\mathrm{H}_{2}$; and solid phase: Ru-based catalyst) at $150{ }^{\circ} \mathrm{C}$ under $5 \mathrm{MPa}$ of $\mathrm{H}_{2}$ pressure in the presence of suspended $\mathrm{ZrO}_{2}$, which was added to avoid the agglomeration of the catalyst. Based on this process, Asahi-Kasei developed the first commercial plant for the product of cyclohexene in 1990 that produced $60000 \mathrm{t}$ of this material per year via the selective hydrogenation of benzene.

Supported [1-24] and unsupported [25-33] Ru-based catalysts have been investigated extensively. Although numerous reports have been published in the literature pertaining to the development and application of supported Ru-based catalysts, there have been no reports, to the best of our knowledge, concerning the commercial application of these catalysts for the selective hydrogenation of benzene. Considerable research efforts have been devoted to the development of unsupported Ru-based catalysts by Liu and his team in China [16-24]. To date, Ru-black promoted with $\mathrm{ZnO}$ (designated as $\mathrm{Ru}-\mathrm{Zn}$ ) has been widely used by numerous researchers for the selective hydrogenation of benzene, where it has been reported to exhibit a high level of reactivity [6-11,20,22]. Ru-Zn catalysts have been prepared by a variety of different methods, including coprecipitation [6-11,20,22] and chemical reduction [17]. The process involved in the coprecipitation method is operationally simple, and the commercial Ru-Zn catalyst used in Asahi-Kasei process is also prepared by this method. Liu et al. [20,22] have conducted detailed research pertaining to the preparation of $\mathrm{Ru}$-Zn catalysts using the coprecipitation method and the subsequent evaluation of their catalytic activity. However, the $\mathrm{Ru}$-Zn catalysts generated in these studies were coprecipitated under high alkaline conditions and washed with an alkaline solution following their preparation by the coprecipitation method, which is similar to the process used by Asahi-Kasei [8]. Using processes of this type, it can be difficult to control the Ru and $\mathrm{Zn}$ contents in the final $\mathrm{Ru}-\mathrm{Zn}$ catalysts because $\mathrm{Zn}$ and even $\mathrm{Ru}$ atoms can be lost during the coprecipitation and washing processes under the highly alkaline conditions. Furthermore, a large amount of alkaline waste water is produced during these processes.

In this study, we have developed a new process for preparing Ru-Zn catalysts using the coprecipitation method under low alkaline conditions, whilst also avoiding the need to wash the resulting catalyst with an alkaline solution. Furthermore, the catalysts produced in this way showed high selectivity towards cyclohexene during the selective hydrogenation of benzene. The effect of the amount of $\mathrm{ZnCl}_{2}$ added to the coprecipitation solution was investigated, as well as the impact of several other reaction conditions (e.g., stirring rate) and the amount of $\mathrm{ZnSO}_{4}$. The stability of the optimal $\mathrm{Ru}-\mathrm{Zn}$ catalyst was also evaluated.

\section{Experimental}

\subsection{Catalyst preparation}

\subsubsection{Low alkaline conditions}

The $\mathrm{Ru}-\mathrm{Zn}$ catalysts were prepared as follows. A NaOH solution $(4 \%(\mathrm{~m} / \mathrm{V}), 35 \mathrm{~mL})$ was quickly added into a stirred solution of $\mathrm{RuCl}_{3} \cdot x \mathrm{H}_{2} \mathrm{O}$ (2.5 g; Shenyang Nonferrous Metal Research Institute, Shenyang, China; Ru content: 36-38 wt\%) and the desired amount of $\mathrm{ZnCl}_{2}$ (Sinopharm Chemical Reagent Co., Ltd, Shanghai, China) in water $(250 \mathrm{~mL})$, and the resulting solution was stirred for $2 \mathrm{~h}$ at $80{ }^{\circ} \mathrm{C}$. The reaction mixture was then cooled to ambient temperature and stirred overnight. The supernatant $(\sim 135 \mathrm{~g})$ was decanted, and the remaining mixture was placed into a $250 \mathrm{~mL}$ Teflon-lined autoclave. $\mathrm{H}_{2}$ was fed into the autoclave after the system had been purged five times, and the purged mixture was reduced under $5 \mathrm{MPa}$ of $\mathrm{H}_{2}$ pressure at $150{ }^{\circ} \mathrm{C}$ and a stirring rate of $1000 \mathrm{r} / \mathrm{min}$ for $3 \mathrm{~h}$. The mixture was then cooled to ambient temperature, and the resulting $\mathrm{Ru}-\mathrm{Zn}$ black powder was washed with water until no $\mathrm{Cl}^{-}$ could be detected. The resulting Ru-Zn catalysts were stored in water, and a series of Ru-Zn catalysts (Ru-Zn-0 to Ru-Zn-4) was prepared by changing the amount of $\mathrm{ZnCl}_{2}$ added to the coprecipitation solution. The details of these catalysts are shown in Table 1.

\subsubsection{High alkalinity conditions}

The Ru-Zn-5 catalyst was prepared according to the procedures from the literature $[8,20,22]$. Briefly, a stirred solution of $\mathrm{RuCl}_{3} \cdot x \mathrm{H}_{2} \mathrm{O}(2.5 \mathrm{~g})$ and $\mathrm{ZnCl}_{2}(3.25 \mathrm{~g})$ in $\mathrm{H}_{2} \mathrm{O}(250 \mathrm{~mL})$ was treated with a $\mathrm{NaOH}$ solution $(30 \%(\mathrm{~m} / \mathrm{V}), 35 \mathrm{~mL})$, and the resulting mixture was agitated for $2 \mathrm{~h}$ at $80^{\circ} \mathrm{C}$. The mixture was then cooled to ambient temperature to give a black precipitate, which was washed three times with a $\mathrm{NaOH}$ solution $4 \%(\mathrm{~m} / \mathrm{V})$

Table 1

$\mathrm{Zn}$ contents in the Ru-Zn catalysts and their textural properties.

\begin{tabular}{|c|c|c|c|c|c|c|c|c|}
\hline Catalyst & $\begin{array}{c}\mathrm{ZnCl}_{2} \\
(\mathrm{~g})\end{array}$ & $\begin{array}{c}\mathrm{pH} \text { of reduction } \\
\text { solution }\end{array}$ & $\begin{array}{l}\mathrm{Zn} / \mathrm{Ru}^{\mathrm{a}} \\
(\mathrm{m} / \mathrm{m})\end{array}$ & $\begin{array}{c}\text { Zn content }{ }^{\mathrm{b}} \\
(\mathrm{wt} \%)\end{array}$ & $\begin{array}{l}\mathrm{Zn} / \mathrm{Ru}^{\mathrm{b}} \\
(\mathrm{m} / \mathrm{m})\end{array}$ & $\begin{array}{c}\text { Surface area } \\
\left(\mathrm{m}^{2} / \mathrm{g}\right)\end{array}$ & $\begin{array}{l}\text { Pore volume } \\
\left(\mathrm{cm}^{3} / \mathrm{g}\right)\end{array}$ & $\begin{array}{c}\text { Pore size }^{c} \\
(\mathrm{~nm})\end{array}$ \\
\hline Ru-Zn-0 & 0.00 & $>12$ & 0.00 & 0.0 & 0.00 & 71.7 & 0.34 & 19.2 \\
\hline Ru-Zn-1 & 0.15 & $>11$ & 0.08 & 7.6 & 0.10 & 72.8 & 0.32 & 17.0 \\
\hline $\mathrm{Ru}-Z \mathrm{n}-2$ & 0.30 & $\sim 10$ & 0.16 & 13.4 & 0.20 & 68.9 & 0.29 & 16.0 \\
\hline $\mathrm{Ru}-\mathrm{Zn}-3$ & 0.45 & $\sim 6$ & 0.24 & 16.7 & 0.26 & 58.7 & 0.24 & 17.0 \\
\hline $\mathrm{Ru}-\mathrm{Zn}-4$ & 0.60 & $\sim 6$ & 0.32 & 19.7 & 0.31 & 59.8 & 0.24 & 15.3 \\
\hline $\mathrm{Ru}-Z n-5^{\mathrm{d}}$ & 3.25 & $>13$ & 1.73 & 9.6 & 0.13 & - & - & - \\
\hline
\end{tabular}

${ }^{a}$ Theoretical value. ${ }^{b}$ Measured by ICP. ${ }^{c}$ BJH desorption average pore diameter (4V/A). ${ }^{d} 30 \% \mathrm{NaOH}$ aq. solution. 
after the supernatant had been removed by decantation. The resulting black precipitate was dispersed in a $\mathrm{NaOH}$ solution $(5 \%(\mathrm{~m} / \mathrm{V}), 150 \mathrm{~mL})$ and charged into a $250 \mathrm{~mL}$ Teflon-lined autoclave. The reduction process used in this particular case was similar to the method described above, except the reduction time was increased to $12 \mathrm{~h}$. The reduction mixture was then cooled to ambient temperature, and the resulting $\mathrm{Ru}-\mathrm{Zn}$ black powder was washed three times with a $\mathrm{NaOH}$ solution $5 \%(\mathrm{~m} / \mathrm{V})$, and then washed with water until no $\mathrm{Cl}^{-}$could be detected. The resulting Ru-Zn catalyst was stored in water.

\subsection{Catalyst characterization}

The $\mathrm{Ru}-\mathrm{Zn}$ catalysts prepared above were stored in water immediately after their preparation and were subsequently vacuum-dried at $40{ }^{\circ} \mathrm{C}$ prior to being characterized. The Ru and Zn contents in the catalysts were measured on an Optima 7000 DV ICP-OES Spectrometer (PerkinElmer, USA). X-ray powder diffraction (XRD) patterns were collected on an Ultima IV diffractometer (Ultima, Rigaku, Japan) using $\mathrm{Cu} K_{\alpha}$ radiation. $\mathrm{N}_{2}$ physisorption experiments were performed on a Micromeritics ASAP 2020 system (USA). The total surface area of each catalyst was obtained using the BET equation, and the pore size was determined by BJH desorption analysis.

Temperature-programmed reduction (TPR) experiments were performed on a PX200 Multi-sorption equipment (Tianjin Golden Eagle Technology Co., Ltd, China). In a typical run, a sample of the catalysts (without reduction) that was kept in water ( $\sim 5 \mathrm{mg}$ dry basis) was added with water directly to the reactor where it was heated at $300{ }^{\circ} \mathrm{C}$ for $2 \mathrm{~h}$ under Ar stream (10 $\mathrm{mL} / \mathrm{min}$ ). The $\mathrm{H}_{2}$-TPR curves were subsequently determined by passing $5 \% \mathrm{H}_{2}-95 \%$ Ar stream (20 mL/min) through the preheated sample whilst the temperature was increased from 25 to $500{ }^{\circ} \mathrm{C}$ at a rate of $10{ }^{\circ} \mathrm{C} / \mathrm{min}$. A thermal conductivity detector (TCD) was used to determine the amount of $\mathrm{H}_{2}$ consumed by this process.

\subsection{Reactivity testing}

The selective hydrogenation of benzene was performed in a $250 \mathrm{~mL}$ autoclave (316L stainless steel or hastelloy C276, Beijing Century Senlong Experimental Apparatus Co., Ltd, China) with a magnetic stirrer. In a typical reaction, the autoclave was charged with water $(70 \mathrm{~mL}), \mathrm{Ru}-\mathrm{Zn}$ catalyst $(0.12 \mathrm{~g}$, dry basis), $\mathrm{ZnSO}_{4} \cdot 7 \mathrm{H}_{2} \mathrm{O}$ (8.4 g), and $\mathrm{ZrO}_{2}$ powder (0.6 g; RC-100, Daiichi Kigenso Kagaku Kogyo Co., Ltd, Japan). $\mathrm{H}_{2}$ gas was fed into the autoclave (1.0 MPa) immediately after it had been purged 5 times with $\mathrm{N}_{2}$, and the autoclave was then heated at a stirring rate of $300 \mathrm{r} / \mathrm{min}$. Benzene ( $35 \mathrm{~mL}$ ) was added to the autoclave when the temperature reached $150{ }^{\circ} \mathrm{C}$, and the $\mathrm{H}_{2}$ pressure and the stirring rate were adjusted to $5 \mathrm{MPa}$ and $1200 \mathrm{r} / \mathrm{min}$, respectively. The reaction was then stirred at $150{ }^{\circ} \mathrm{C}$ for $10-60$ min. The products in the organic phase were analyzed by GC on a GC-1690 system (Hangzhou Kexiao) equipped with an FID detector. The resulting GC data were used to calculate the benzene conversion and cyclohexene selectivity. The specific activity of the catalyst $\left(\gamma_{40}\right)$ was defined as the converted amount (g) of benzene per hour over $1 \mathrm{~g}$ of Ru at a conversion of $40 \%$.

For experiments concerning the recyclability of the Ru-Zn-3 catalyst, the organic phase was removed from the autoclave by suction, and the remaining slurry containing the $\mathrm{Ru}-\mathrm{Zn}$ catalyst, $\mathrm{ZrO}_{2}$, and $\mathrm{ZnSO}_{4}$ was used in the next experiment. Experiments involving the recycled catalyst were conducted under the same conditions as those described above.

\section{Results and discussion}

\subsection{Catalyst characterization results}

As shown in Table 1, five unsupported Ru-Zn catalysts with different $\mathrm{Zn}$ contents (i.e., Ru-Zn-0 to 4) were prepared by the coprecipitation method under low alkaline conditions. The amount of the $\mathrm{NaOH}$ precipitant (4\%) was kept constant in all of the experiments involving the addition of different amounts of $\mathrm{ZnCl}_{2}$. The $\mathrm{pH}$ of the precipitation solution therefore decreased gradually as the amount of $\mathrm{ZnCl}_{2}$ added to the mixture increased. The $\mathrm{pH}$ value of the reduction solution was less than 7 when the amount of $\mathrm{ZnCl}_{2}$ added to the solution was greater than $0.45 \mathrm{~g}$. The $\mathrm{Ru}$ and $\mathrm{Zn}$ contents in the precipitation and reduction solutions were measured by ICP, and found to be lower than $0.25 \mathrm{ppm}$ in both cases, which indicated that very little $\mathrm{Ru}$ and $\mathrm{Zn}$ were lost to the solution during the precipitation and reduction processes. This result was confirmed by the similarity in the $\mathrm{Ru} / \mathrm{Zn}$ ratios between the ICP results and the theoretical values.

If $\mathrm{Ru}$ and $\mathrm{Zn}$ existed in their respective atomic states in the catalysts, then the theoretical total contents of $\mathrm{Ru}$ and $\mathrm{Zn}$ in Ru-Zn- 0 to 4 would be $0.91,0.98,1.06,1.13$, and 1.20 g, respectively. In practice, the final mass of $\mathrm{Ru}$ and $\mathrm{Zn}$ in the catalysts synthesized in the current study (i.e., Ru-Zn-0 to 4) was 0.90, $0.96,1.11,1.31$, and $1.41 \mathrm{~g}$, respectively. When the $\mathrm{Zn}$ content in the catalysts was higher than 16.7 wt\% (e.g., Ru-Zn-3 and 4), the final mass of the catalysts was higher than the theoretical values. These results therefore suggested that these catalysts could also be made up of some Ru and $\mathrm{Zn}$ oxide species. Fig. 1 shows the XRD patterns of all five catalysts. When the $\mathrm{Zn}$ content was lower than 13.4 wt\% (e.g., Ru-Zn-0 to 2), the XRD pattern only contained diffraction peaks that could be assigned to

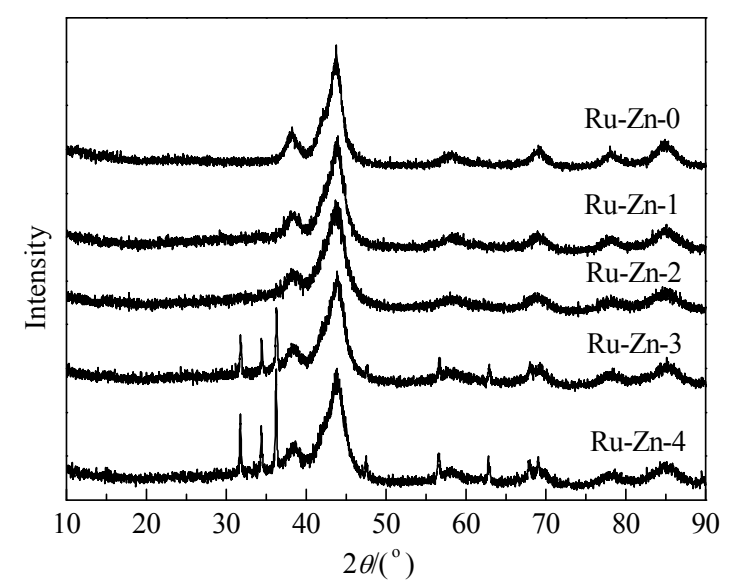

Fig. 1. XRD patterns of the Ru-Zn catalysts with different $\mathrm{Zn}$ contents. 
the metallic Ru phase $\left(2 \theta=38.4^{\circ}, 44.0^{\circ}, 58.3^{\circ}, 69.4^{\circ}, 78.4^{\circ}\right.$, and $\left.84.7^{\circ}\right)$. Evaluation of the Ru crystallite size from the XRD patterns using the Scherrer formula indicated that the nature of the $\mathrm{Zn}$ species had very little impact on the Ru crystallite size $(\sim 4.0 \mathrm{~nm})$ in the $\mathrm{Ru}-\mathrm{Zn}$ catalysts. When the $\mathrm{Zn}$ content was higher than $16.7 \mathrm{wt} \%$, the XRD patterns contains seven diffraction peaks that could be assigned to the hexagonal phases of $\mathrm{ZnO}\left(2 \theta=31.8^{\circ}, 34.4^{\circ}, 36.3^{\circ}, 47.5^{\circ}, 56.6^{\circ}, 62.9^{\circ}\right.$, and $\left.68^{\circ}\right)$, which indicated the presence of $\mathrm{ZnO}$ in the $\mathrm{Ru}-\mathrm{Zn}-3$ and $\mathrm{Ru}-\mathrm{Zn}-4$ catalysts. The XRD patterns of the Ru-Zn catalysts before the reduction did not contain any peaks corresponding to crystals (data not shown).

The XRD peaks corresponding to the $\mathrm{ZnO}$ phase were also observed for the Ru-Zn-3 catalyst after the reduction time was extended to $6 \mathrm{~h}$ (data not shown), which indicated that the $\mathrm{ZnO}$ was difficult to reduce at $150{ }^{\circ} \mathrm{C}$ under $5 \mathrm{MPa}$ of $\mathrm{H}_{2}$ pressure. These results also indicated that the $\mathrm{ZnO}$ particles were highly dispersed in the Ru-Zn catalysts when the Zn content was lower than 13.4 wt\% (e.g., Ru-Zn-1 and Ru-Zn-2). The XRD peaks corresponding to $\mathrm{Ru}$ oxide were not observed for these catalysts, which indicated that they did not contain Ru oxides or the $\mathrm{Ru}$ oxides were highly dispersed in all of the catalysts.

To compare the properties of the Ru-Zn catalysts prepared under low alkaline conditions with those of the corresponding catalyst prepared under high alkaline conditions, we prepared $\mathrm{Ru}-\mathrm{Zn}-5$ by adding a $30 \% \mathrm{NaOH}$ solution to the precipitation solution, and washing the resulting catalyst in $\mathrm{NaOH}$ aqueous solution $(4 \%(\mathrm{~m} / \mathrm{V}))$ before reducing it in a $\mathrm{NaOH}$ solution $(5 \%$ $(\mathrm{m} / \mathrm{V})$ ). As shown in Table 1 , the final $\mathrm{Zn}$ content of Ru-Zn-5 was only $9.6 \mathrm{wt} \%$ with a $\mathrm{Zn} / \mathrm{Ru}$ ratio of 0.13 (as determined from the ICP data). This $\mathrm{Zn} / \mathrm{Ru}$ ratio was much lower than that of the theoretical value (1.73) even though $\mathrm{ZnCl}_{2}$ (3.25 g) was added to the precipitation solution. The XRD pattern of Ru-Zn-5 did not contain any diffraction peaks corresponding to the $\mathrm{ZnO}$ phase (data not shown), which indicated that most of the $\mathrm{Zn}$ species must have been lost to the solution and that it is therefore difficult to control the $\mathrm{Zn}$ content in $\mathrm{Ru}-\mathrm{Zn}$ catalysts prepared under high alkaline conditions.

Fig. 2 shows the $\mathrm{H}_{2}$-TPR profiles of the Ru-Zn-0 and Ru-Zn-3 catalysts without reduction. The reduction temperature for the Ru-Zn-0 catalyst was $111.3^{\circ} \mathrm{C}$, clearly much lower than that of

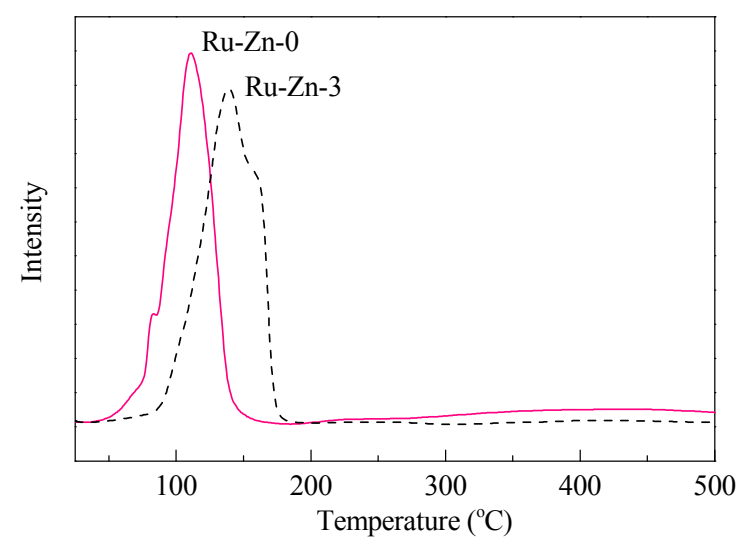

Fig. 2. $\mathrm{H}_{2}$-TPR profiles of catalysts $\mathrm{Ru}-\mathrm{Zn}-0$ and $\mathrm{Ru}-\mathrm{Zn}-3$ before reduction. the Ru-Zn-3 catalyst, which was $139.3^{\circ} \mathrm{C}$. This difference in the reduction temperatures of two catalysts indicated that the addition of $\mathrm{Zn}$ species effectively inhibited the reduction of the $\mathrm{Ru}$ species. The $\mathrm{H}_{2}$-TPR profile of the $\mathrm{Ru}-\mathrm{Zn}-3$ catalyst contained a peak with shoulders between 100 and $170{ }^{\circ} \mathrm{C}$, which were attributed to the step-by-step reduction of $\mathrm{RuO}_{2}$ to metallic $\mathrm{Ru}$ [22]. Similar $\mathrm{H}_{2}$-TPR profiles have been reported in the literature for $\mathrm{Ru}-\mathrm{Zn}$ catalysts containing different $\mathrm{Zn}$ contents by Liu and his coworkers [22]. The temperatures required for the complete reduction of all of the $\mathrm{Ru}-\mathrm{Zn}$ catalysts were close to the reaction temperature $150{ }^{\circ} \mathrm{C}$, which indicated that metallic $\mathrm{Ru}$ was the only $\mathrm{Ru}$ species present in the catalyst when it was heated at $150^{\circ} \mathrm{C}$ under $5 \mathrm{MPa}$ of $\mathrm{H}_{2}$ pressure.

The $\mathrm{H}_{2}$-TPR profiles of the reduced $\mathrm{Ru}-\mathrm{Zn}$ catalysts were also measured. The reduced $\mathrm{Ru}-\mathrm{Zn}$ catalysts that had been kept in water were added directly to the $\mathrm{H}_{2}$-TPR reactor. The samples were then dried and preheated at $300{ }^{\circ} \mathrm{C}$ in $\mathrm{Ar}$ gas for $2 \mathrm{~h}$. The $\mathrm{H}_{2}$-TPR profiles of the resulting materials are shown in Fig. 3 . These results revealed that the reduction peak appeared at room temperature for the catalysts with low $\mathrm{Zn}$ contents (e.g., Ru-Zn-1 and Ru-Zn-2), and that the reduction process started from $30{ }^{\circ} \mathrm{C}$ and peaked at temperatures greater than $56^{\circ} \mathrm{C}$ for the catalysts with high $\mathrm{Zn}$ contents (e.g., Ru-Zn-3 and Ru-Zn-4). Furthermore, the reduction peak of the catalyst with the lowest Zn content (i.e., Ru-Zn-1) was much larger than that of a catalyst with a high Zn content (e.g., Ru-Zn-3) (Fig. 4), which indicated that the catalysts with low $\mathrm{Zn}$ contents could be readily reduced and oxidized. In fact, the $\mathrm{H}_{2}$-TPR reduction peaks of the catalysts reduced in the autoclave and subsequently vacuum-dried were much larger than those of the catalysts reduced in the autoclave, stored in water and directly added to the TPR reactor, especially for the catalysts with low $\mathrm{Zn}$ contents. Taken together, these results indicated that the reduced $\mathrm{Ru}-\mathrm{Zn}$ catalysts could be readily oxidized, especially those with low $\mathrm{Zn}$ contents.

Interestingly, it was found that catalysts prepared with the same amount of $\mathrm{RuCl}_{3} \cdot x \mathrm{H}_{2} \mathrm{O}$ but different amounts of $\mathrm{ZnCl}_{2}$ exhibited different sedimentation behavior in water. As shown in Fig. 5, the dispersion degree of the catalyst in water increased with increasing $\mathrm{Zn}$ content. Thus, catalysts with high $\mathrm{Zn}$ contents (e.g., Ru-Zn-3 and Ru-Zn-4) showed good disper-

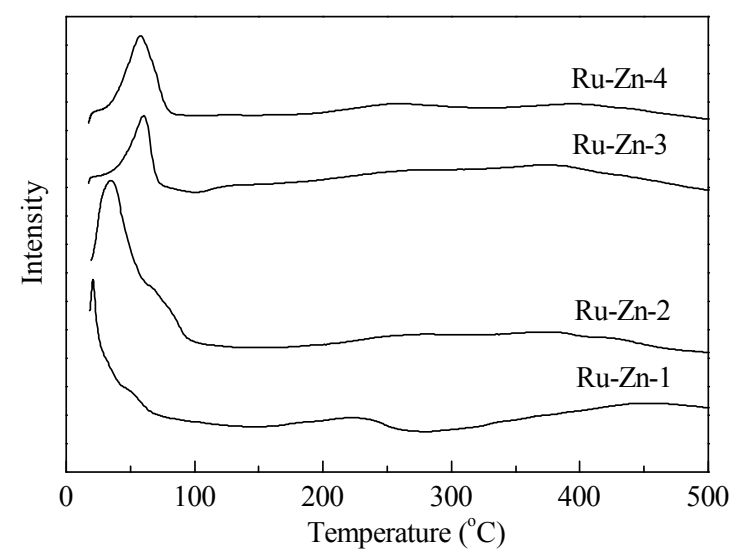

Fig. 3. $\mathrm{H}_{2}-\mathrm{TPR}$ profiles of Ru-Zn catalysts with different $\mathrm{Zn}$ contents after reduction. 


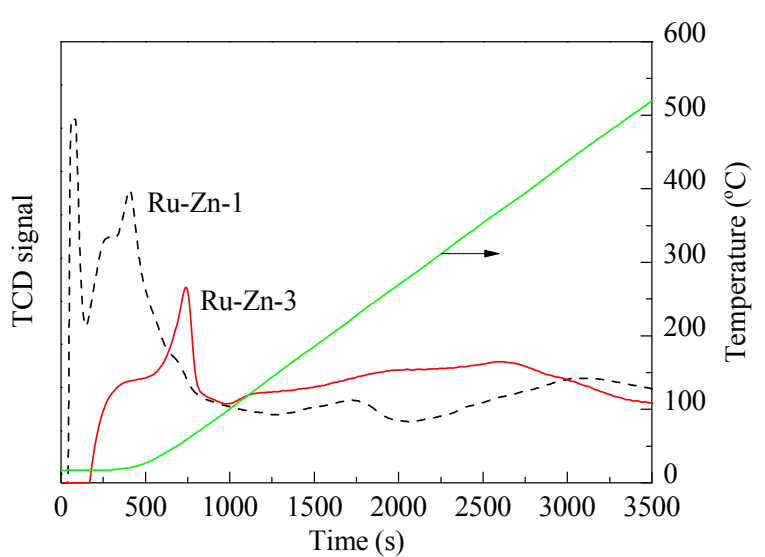

Fig. 4. $\mathrm{H}_{2}$-TPR profiles of catalysts $\mathrm{Ru}-\mathrm{Zn}-1$ and $\mathrm{Ru}-\mathrm{Zn}-3$ after reduction.

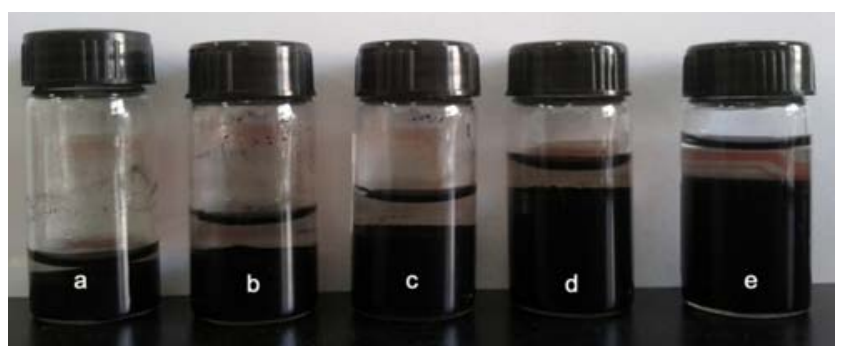

Fig. 5. Photos of Ru-Zn catalysts with different Zn contents. (a) Ru-Zn-0; (b) Ru-Zn-1; (c) Ru-Zn-2; (d) Ru-Zn-3; (e) Ru-Zn-4.

sion in water. There are three possible reasons for these differences in the dispersion behavior, including (1) the total amount of the catalyst increases with increasing Zn content; (2) the hydrophilicity of the catalyst increases with increasing $\mathrm{Zn}$ content; and (3) the Ru species can be readily reduced in the catalysts with low $\mathrm{Zn}$ contents, and the resulting catalyst can readily aggregate after reduction.

The textural properties of the Ru-Zn catalysts were characterized by $\mathrm{N}_{2}$ physisorption, and the results are shown in Table 1. As mentioned above, the Ru-Zn catalysts were composed of $\mathrm{Ru}$ nanoparticles ( $\sim 4 \mathrm{~nm}$ in diameter). The nanoparticles readily aggregated, which meant that there were mesopores in the catalysts after they had been dried. It was found that the BET surface areas and pore volumes of the catalysts with high $\mathrm{Zn}$ contents (e.g., Ru-Zn-3 and Ru-Zn-4) decreased significantly compared with the catalysts with low $\mathrm{Zn}$ contents. This result was consistent with the appearance of a ZnO phase in these two catalysts. Another reason for this decrease in the BET surface areas and pore sizes of these catalysts could be a decrease in the $\mathrm{Ru}$ nanoparticle contents in these catalysts. The pore sizes of catalysts containing Zn were slightly smaller than that of the catalyst without Zn. Despite these minor differences, there was no clear trend between the pore size and the $\mathrm{Zn}$ content in the catalysts.

\subsection{Catalytic properties}

\subsubsection{Effects of the $\mathrm{Zn}$ content}

The catalytic performance of the Ru-Zn catalysts with different $\mathrm{Zn}$ contents was investigated for the selective hydro- genation of benzene to cyclohexene. The performance of the $\mathrm{Ru}-\mathrm{Zn}$ catalysts was evaluated in terms of the reaction time, benzene conversion, cyclohexene selectivity and yield, and the results are summarized in Table 2. It is noteworthy that the reaction time was adjusted according to the reactivity over the catalyst to obtain similar levels of benzene conversion. The $\mathrm{Ru}-\mathrm{Zn}-0$ catalyst, which did not contain any Zn, gave the lowest selectivity for cyclohexene over all the catalysts tested, despite also providing the lowest benzene conversion. Based on the reaction time required over the different catalysts to obtain similar levels of benzene conversion, it became clear that the activity of the catalysts decreased with increasing $\mathrm{Zn}$ content, whereas the selectivity and yield of cyclohexene increased. In other words, the addition of $\mathrm{Zn}$ led to significant improvements in the selectivity and yield of cyclohexene. As proposed in the literature [11,22], the main reason for this improvement in the selectivity and yield of cyclohexene is that the $\mathrm{Zn}$ component in the catalysts inhibits the resorption of the cyclohexene product onto the surface of the catalyst, and therefore suppresses the hydrogenation of cyclohexene to cyclohexane. As shown in Table 2, the Ru-Zn-0 catalyst provided lower levels of benzene conversion and cyclohexene selectivity than the Ru-Zn-1 catalyst after the same reaction time. As described above in Section 3.1 , these differences in the performance of the catalysts could be attributed to the poorer dispersion of the Ru-Zn-0 catalyst in water. No significant increase was observed in the selectivity of the catalyst $\mathrm{Ru}-\mathrm{Zn}-4$ although a longer reaction time of $60 \mathrm{~min}$ was needed. The cyclohexene selectivity over the Ru-Zn-3 catalyst was higher than $80 \%$ with benzene conversion of $47 \%$, and it should be possible to separate the cyclohexene and cyclohexane products by solvent extraction because of their similar boiling points. Naturally, the separation costs associated with processes with high cyclohexene selectivity will be lower than those incurred for processes with low cyclohexene selectivity. With this in mind, a cyclohexene selectivity of greater than $80 \%$ is required by the fine chemicals industry [11]. The performance characteristics of the $\mathrm{Ru}-\mathrm{Zn}-3$ catalyst clearly meet this need, indicating that the Ru-Zn-3 catalyst could potentially be used in commercial application. The Ru-Zn-3 catalyst was used to investigate the effects of several other factors on the performance of the hydrogenation reaction, and the results are discussed in detail below. According to the literature $[20,22]$, the best $\mathrm{Zn}$ content for the hydrogenation of benzene to cyclohexene is $8-10 \mathrm{wt} \%$. The catalysts described in those studies were prepared under highly alkaline conditions and

Table 2

Effects of the Zn content on the reaction properties.

\begin{tabular}{lcccc}
\hline Catalyst & $\begin{array}{c}\text { Reaction time } \\
(\min )\end{array}$ & $\begin{array}{c}\text { Conversion } \\
(\%)\end{array}$ & $\begin{array}{c}\text { Selectivity } \\
(\%)\end{array}$ & $\begin{array}{c}\text { Yield } \\
(\%)\end{array}$ \\
\hline $\mathrm{Ru}-\mathrm{Zn}-0$ & 10 & 41.0 & 47.4 & 19.4 \\
$\mathrm{Ru}-\mathrm{Zn}-1$ & 10 & 55.2 & 58.8 & 32.4 \\
$\mathrm{Ru}-\mathrm{Zn}-2$ & 20 & 47.3 & 75.0 & 35.5 \\
$\mathrm{Ru}-\mathrm{Zn}-3$ & 45 & 47.2 & 80.7 & 38.1 \\
$\mathrm{Ru}-\mathrm{Zn}-4$ & 60 & 47.9 & 81.9 & 39.2 \\
$\mathrm{Ru}-\mathrm{Zn}-5$ & 20 & 50.4 & 65.8 & 33.2 \\
\hline
\end{tabular}

Reaction conditions: catalyst $0.12 \mathrm{~g}, \mathrm{ZrO}_{2} 0.6 \mathrm{~g}, \mathrm{ZnSO}_{4} \cdot 7 \mathrm{H}_{2} \mathrm{O} 8.4 \mathrm{~g}, \mathrm{C}_{6} \mathrm{H}_{6}$ $35 \mathrm{~mL}, \mathrm{H}_{2} \mathrm{O} 70 \mathrm{~mL}, 150{ }^{\circ} \mathrm{C}, 5 \mathrm{MPa}$ of $\mathrm{H}_{2}$ pressure, stirring rate 1200 $\mathrm{r} / \mathrm{min}$. 
had to be pretreated in the aqueous solution of $\mathrm{ZnSO}_{4} \cdot 7 \mathrm{H}_{2} \mathrm{O}$ and suspended $\mathrm{ZrO}_{2}$ solution before the reaction. The $\mathrm{Ru}-\mathrm{Zn}-3$ catalyst was prepared under low alkaline conditions and did not require a pretreatment process. As shown in Table 2, the Ru-Zn-5 catalyst, which was prepared under highly alkaline conditions, showed lower selectivity as well as a lower yield of cyclohexene than the other catalysts prepared under low alkaline conditions (e.g., Ru-Zn-2 to 4). The XRD pattern of the Ru-Zn-5 catalyst did not contain any peaks that could be assigned to $\mathrm{ZnO}$ crystals (data no shown). Based on the results of the XRD analysis (Fig. 1) and the outcome of the reactions (Table 2), it was proposed that the presence of $\mathrm{ZnO}$ crystals in the Ru-based catalysts is critical to obtaining high selectivity for cyclohexene (>80\%).

\subsubsection{Effects of the stirring rate}

The catalytic performance of the Ru-Zn-3 catalyst was investigated under a variety of different stirring rates, and the results are shown in Table 3. The results showed that the stirring rate had very little impact on the benzene conversion and yield of cyclohexene when it was between 1100 and 1300 $\mathrm{r} / \mathrm{min}$. Struijk et al. [13] reported a strong increase in the initial rate of hydrogen uptake with the stirring rate as the stirring rate was below $1000 \mathrm{r} / \mathrm{min}$, and that the rate of hydrogen uptake increased only gradually at stirring rates above 1000 $\mathrm{r} / \mathrm{min}$. At stirring rates above $1000 \mathrm{r} / \mathrm{min}$, the diffusional retardation of the reaction rate due to the mass transport of hydrogen at the gas/liquid interface and of benzene at the liquid/liquid interface is minimized. Liu's group [19] also found that the reaction selectivity for cyclohexene increased with increasing stirring rate when it was slower than $800 \mathrm{r} / \mathrm{min}$. Struijk et al. [13] reported that stirring rates of higher than $2000 \mathrm{r} / \mathrm{min}$ led to the attrition of the catalyst, with the catalyst also adhering to the inner wall of the reactor. A stirring rate of $1400 \mathrm{r} / \mathrm{min}$ was used by Liu et al. [22] in their study of the effect of zinc contents. The results of the current study revealed that a stirring rate of $1100-1300 \mathrm{r} / \mathrm{min}$ was optimal for the production rate of cyclohexene, at least when a magnetic stirrer was used with our reactor system.

\subsubsection{Effect of the amount of $\mathrm{ZnSO}_{4}$}

The zinc sulphate $\left(\mathrm{ZnSO}_{4} \cdot 7 \mathrm{H}_{2} \mathrm{O}\right)$ concentration was varied in a series of separate experiments designed to develop a deeper understanding of the influence of salts on the performance of the Ru-Zn catalyst, and the results are shown in Fig. 6. The results show that the addition of a small amount of $\mathrm{ZnSO}_{4}$ suppressed the reaction rate, but also led to a significant increase in the selectivity for cyclohexene. The initial selectivity for cy-

Table 3

Effect of stirring rate on the reaction properties over the Ru-Zn-3 catalyst.

\begin{tabular}{lccc}
\hline Stirring rate (r/min) & Conversion (\%) & Selectivity (\%) & Yield (\%) \\
\hline 1100 & 47.8 & 83.9 & 40.1 \\
1200 & 48.3 & 82.3 & 39.8 \\
1300 & 47.7 & 84.2 & 40.1 \\
\hline
\end{tabular}

Reaction conditions: $\mathrm{Ru}-\mathrm{Zn}-3$ catalyst $0.12 \mathrm{~g}, \mathrm{ZrO}_{2} 0.6 \mathrm{~g}, \mathrm{ZnSO}_{4} \cdot 7 \mathrm{H}_{2} \mathrm{O} 8.4$ g, $\mathrm{C}_{6} \mathrm{H}_{6} 35 \mathrm{~mL}, \mathrm{H}_{2} \mathrm{O} 70 \mathrm{~mL}, 150{ }^{\circ} \mathrm{C}, 5 \mathrm{MPa}$ of $\mathrm{H}_{2}$ pressure, $45 \mathrm{~min}$.

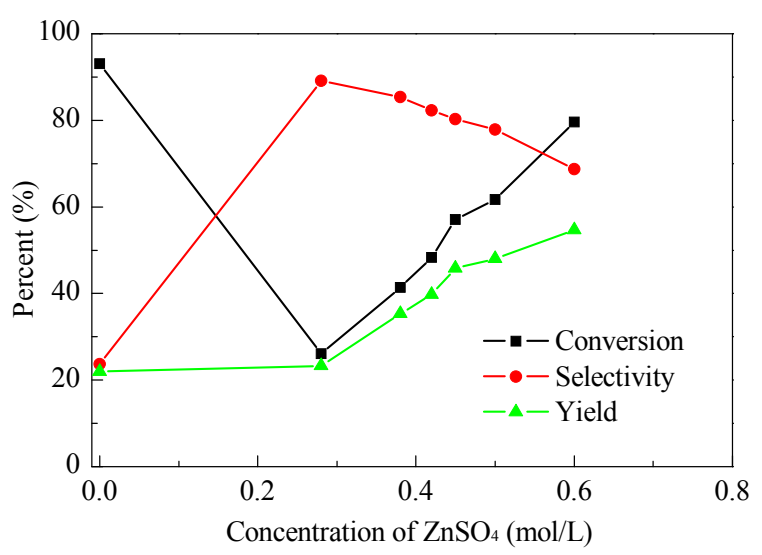

Fig. 6. Effect of the $\mathrm{ZnSO}_{4}$ concentration on the outcome of the reaction. Reaction conditions: Ru-Zn-3 catalyst $0.12 \mathrm{~g}, \mathrm{ZrO}_{2} 0.6 \mathrm{~g}, \mathrm{ZnSO}_{4} \cdot 7 \mathrm{H}_{2} \mathrm{O}$ 0.0-12.3 g, $\mathrm{C}_{6} \mathrm{H}_{6} 35 \mathrm{~mL}, \mathrm{H}_{2} \mathrm{O} 70 \mathrm{~mL}, 150{ }^{\circ} \mathrm{C}, 5 \mathrm{MPa}$ of $\mathrm{H}_{2}$ pressure, 45 min, stirring rate $1200 \mathrm{r} / \mathrm{min}$.

clohexene increased significantly from about $23.6 \%$ up to $89.2 \%$, when the $\mathrm{ZnSO}_{4}$ concentration was increased from 0 to $0.3 \mathrm{~mol} / \mathrm{L}$. However, a further increase in the $\mathrm{ZnSO}_{4}$ concentration from 0.30 to $0.60 \mathrm{~mol} / \mathrm{L}$ led to a slight decrease in the selectivity for cyclohexene although the benzene conversion and yield of cyclohexene increased significantly. Although the yield increased with increasing $\mathrm{ZnSO}_{4}$ concentration, the selectivity for cyclohexene was lower than $80 \%$ when the concentration of $\mathrm{ZnSO}_{4}$ was higher than $0.5 \mathrm{~mol} / \mathrm{L}$. The optimal concentration of $\mathrm{ZnSO}_{4}$ was therefore determined to be $0.42-0.45 \mathrm{~mol} / \mathrm{L}$. When the concentration of $\mathrm{ZnSO}_{4}$ was $0.45 \mathrm{~mol} / \mathrm{L}$, the yield of cyclohexene reached $45 \%$ with a selectivity of greater than $80 \%$.

The specific activity $\left(\gamma_{40}\right)$ and selectivity $\left(S_{40}\right)$ of the Ru-Zn-3 catalyst were found to be $166 \mathrm{~g} / \mathrm{g} \cdot \mathrm{h})$ and $85.5 \%$ at $\mathrm{ZnSO}_{4}$ concentration of $0.38 \mathrm{~mol} / \mathrm{L}$, and $185 \mathrm{~g} /(\mathrm{g} \cdot \mathrm{h})$ and $83.0 \%$ at $\mathrm{ZnSO}_{4}$ concentration of $0.42 \mathrm{~mol} / \mathrm{L}$, respectively. Based on commercial estimations, a specific activity $\left(\gamma_{40}\right)$ of greater than $100 \mathrm{~g} /(\mathrm{g} \cdot \mathrm{h})$ is required for the reduction of benzene to cyclohexene together with a selectivity $\left(S_{40}\right)$ of greater than $80 \%$, and the performance characteristics of the Ru-Zn-3 catalyst clearly meet these requirements. Furthermore, the results of the current study are comparable with data from the literature, which gave $\gamma_{40}$ and $S_{40}$ values of $\left.155 \mathrm{~g} / \mathrm{g} \cdot \mathrm{h}\right)$ and $85.5 \%$, respectively [34].

It has been shown that the presence of an aqueous salt solution is essential for obtaining a high yield of cyclohexene in the selective hydrogenation of benzene over Ru-based catalysts [13], and the results of the current study are similar to those reported elsewhere in the literature [14]. Liu et al. [16] investigated the influence of different $\mathrm{Zn}$ ion concentrations and $\mathrm{pH}$ values on the performance of the $\mathrm{Ru}-\mathrm{Fe}-\mathrm{B} / \mathrm{ZrO}_{2}$ catalyst, and found that the optimal concentration of $\mathrm{Zn}^{2+}$ in the slurry was in the range of $0.5-0.6 \mathrm{~mol} / \mathrm{L}$ with a $\mathrm{pH}$ value of $5.4-5.5$. The impact of the salt solution can be explained as follows. $\mathrm{ZnSO}_{4}$ would be chemisorbed onto the surface of the $\mathrm{Ru}$ catalyst, which would result in the $\mathrm{Ru}$ becoming hydrophilic. The $\mathrm{Ru}$ catalyst particles would therefore be surrounded by a layer of water, which would lead to a strong diffusional resistance towards mass transfer of hydrogen and cyclohexene to the $\mathrm{Ru}$ surface. The presence of such a water layer would also slow 


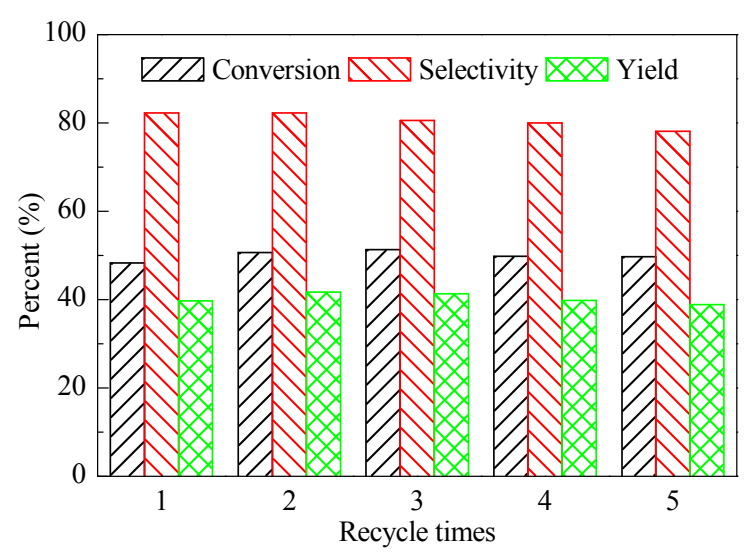

Fig. 7. Recyclability of the Ru-Zn-3 catalyst for the selective hydrogenation of benzene to cyclohexene. Reaction conditions: Ru-Zn-3 catalyst $0.12 \mathrm{~g}, \mathrm{ZrO}_{2} 0.6 \mathrm{~g}, \mathrm{ZnSO}_{4} \cdot 7 \mathrm{H}_{2} \mathrm{O} 8.4 \mathrm{~g}, \mathrm{C}_{6} \mathrm{H}_{6} 35 \mathrm{~mL}, \mathrm{H}_{2} \mathrm{O} 70 \mathrm{~mL}, 150{ }^{\circ} \mathrm{C}, 5$ $\mathrm{MPa}$ of $\mathrm{H}_{2}$ pressure, stirring rate $1200 \mathrm{r} / \mathrm{min}, 45 \mathrm{~min}$.

down the hydrogenation of cyclohexene to cyclohexane because it would suppress the direct hydrogenation of the adsorbed cyclohexene. The presence of a water layer would also slow down the rate of cyclohexene re-adsorption because of the poor solubility of cyclohexene in water. Liu's group [22] recently proposed that the synergistic effect of $\mathrm{ZnO}$ and $\mathrm{ZnSO}_{4}$ enhanced the selectivity for cyclohexene. Namely, the $\left(\mathrm{Zn}(\mathrm{OH})_{2}\right)_{3}\left(\mathrm{ZnSO}_{4}\right)\left(\mathrm{H}_{2} \mathrm{O}\right)_{5}$ salt formed by $\mathrm{ZnO}$ on the surface of the catalyst would react with $\mathrm{ZnSO}_{4}$ and play a key role in improving the selectivity of the catalyst for cyclohexene. However, no explanation has been provided to date in the literature to account for the observed increase in the benzene conversion with increasing $\mathrm{ZnSO}_{4}$ concentration. We propose that the $\mathrm{pH}$ value of the reaction solution decreases with increasing $\mathrm{ZnSO}_{4}$ concentration, which would result in the dissolution of the $\mathrm{ZnO}$ on the surface of the catalyst, leading to an increase in the benzene conversion. However, further research would be required to investigate this hypothesis in detail.

\subsubsection{Stability of the catalyst}

The stability of the Ru-Zn-3 catalyst was investigated. The catalyst was recycled five times without the inclusion of any additives, and the results are shown in Fig. 7. The results show that the benzene conversion was stable above $48 \%$, and that the cyclohexene selectivity and yields were kept above $76 \%$ and $40 \%$ in the first 4 recycles, respectively, which indicated that the catalyst was stable. The activity of the catalyst was slightly decreased in 5 th recycle because of the inevitable loss of catalyst during the recycling process and the occurrence of 4 recycles without regeneration, however, the selectivity to cyclohexene and the yield were still as high as $78.1 \%$ and $38.9 \%$, respectively. These results therefore show that the Ru-Zn-3 catalyst has the potential to be used in industrial application.

\section{Conclusions}

Unsupported Ru-Zn catalysts with different $\mathrm{Zn}$ contents have been successfully prepared using the coprecipitation method under low alkaline conditions. The incorporation of $\mathrm{Zn}$ species led to a decrease in the activity of the Ru catalyst although the selectivity was improved significantly. The optimal $\mathrm{Zn}$ content in the Ru-Zn catalysts was determined to be 16.7 wt $\%$ (i.e., Ru-Zn-3). The use of a stirring rate in the range of 1100 to $1300 \mathrm{r} / \mathrm{min}$ had very little impact on the catalytic reaction. The addition of small amount of $\mathrm{ZnSO}_{4}$ to the reaction solution led to a decrease in the benzene conversion and a significant improvement in the selectivity, with a $\mathrm{ZnSO}_{4}$ concentration of $>0.3 \mathrm{~mol} / \mathrm{L}$ leading to an increase in the benzene conversion. The optimal concentration of $\mathrm{ZnSO}_{4}$ was found to be $0.42-0.45 \mathrm{~mol} / \mathrm{L}$. The selectivity for cyclohexene reached $80 \%$ (yield $>45 \%$ ) when the conversion of benzene was $57 \%$ in $\mathrm{ZnSO}_{4} \cdot 7 \mathrm{H}_{2} \mathrm{O}$ solution of $0.45 \mathrm{~mol} / \mathrm{L}$ under the optimal reaction conditions (i.e., hastelloy reactor, $150{ }^{\circ} \mathrm{C}, 5 \mathrm{MPa}$ of $\mathrm{H}_{2}$ pressure, $1200 \mathrm{r} / \mathrm{min}$ ). The presence of $\mathrm{ZnO}$ crystals in the Ru-based catalysts was very important to obtain a high selectivity for cyclohexene (>80\%). Taken together, these results demonstrate that $\mathrm{Ru}-\mathrm{Zn}$ catalysts prepared under low alkaline conditions could be used for industrial application.

\section{References}

[1] Hartog F, Zwietering P. J Catal, 1963, 2: 79

[2] Drinkard W C Jr. NL Patent 7205832.1972

[3] Odenbrand C U I, Lundin S T. J Chem Technol Biotechnol, 1980, 30: 677

[4] Odenbrand C U I, Lundin S T. J Chem Technol Biotechnol, 1981, 31: 660

[5] Mitsui O, Fukuoka Y. US Patent 4678861.1987

[6] Nagahara H, Konishi M. EP Patent 220 525. 1987

[7] Matsunaga F, Fukuhara H, Yasuhara M. EP Patent 316142.1989

[8] Nagahara H, Konishi M. US Patent 4734 536. 1988

[9] Fukuhara H, Matsunaga F, Nakashima Y. EP Patent 323 192. 1989

[10] Fukuoka Y, Kono M, Nagahara H, Ono M. J Chem Soc Jpn, 1990: 1223

[11] Nagahara H, Ono M, Konishi M, Fukuoka Y. Appl Surf Sci, 1997, 121-122: 448

[12] Struijk J, Scholten J J F. Appl Catal A, 1992, 82: 277

[13] Struijk J, d'Angremond M, Lucas-de Regt W J M, Scholten J J F. Appl Catal A, 1992, 83: 263

[14] Struijk J, Moene R, Van der Kamp T, Scholten J J F. Appl Catal A, 1992, 89: 77

[15] Milone C, Neri G, Donato A, Musolino M G, Mercadante L. J Catal, 1996, 159: 253

[16] Liu S C, Liu Z Y, Zhao S H, Wu Y M, Wang Z, Yuan P. J Nat Gas Chem, 2006, 15: 319

[17] Qin H A, Huang Z X, Liu S C. J Xinyang Normal Univ (Nat Sci Ed) (秦 会安, 黄振旭, 刘寿长. 信阳师范学院学报(自然科学版)), 2007, 20: 350

[18] Liu Z Y, Sun H J, Wang D B, Guo W, Zhou X L, Liu S C, Li Z J. Chin J Catal (刘仲毅, 孙海杰, 王栋斌, 郭伟, 周小莉, 刘寿长, 李中军. 催化学报), 2010, 31: 150

[19] Sun H J, Guo W, Zhou X L, Chen Z H, Liu Z Y, Liu S C. Chin J Catal (孙 海杰, 郭伟, 周小莉, 陈志浩, 刘仲毅, 刘寿长. 催化学报), 2011, 32: 1

[20] Sun H J, Zhang X D, Chen Z H, Zhou X L, Guo W, Liu Z Y, Liu S C. Chin J Catal (孙海杰, 张旭东, 陈志浩, 周小莉, 郭伟, 刘仲毅, 刘寿长. 催化学报), 2011, 32: 224

[21] Sun H J, Jiang H B, Li S H, Dong Y Y, Wang H X, Pan Y J, Liu S C, Tang 


\title{
Graphical Abstract
}

Chin. J. Catal., 2015, 36: 400-407 doi: 10.1016/S1872-2067(14)60231-X

\section{$\mathrm{Ru}-\mathrm{Zn}$ catalysts for selective hydrogenation of benzene using coprecipitation in low alkalinity}

Zhengbao Wang*, Qi Zhang, Xiaofei Lu, Shuangjia Chen, Chunjie Liu Zhejiang University
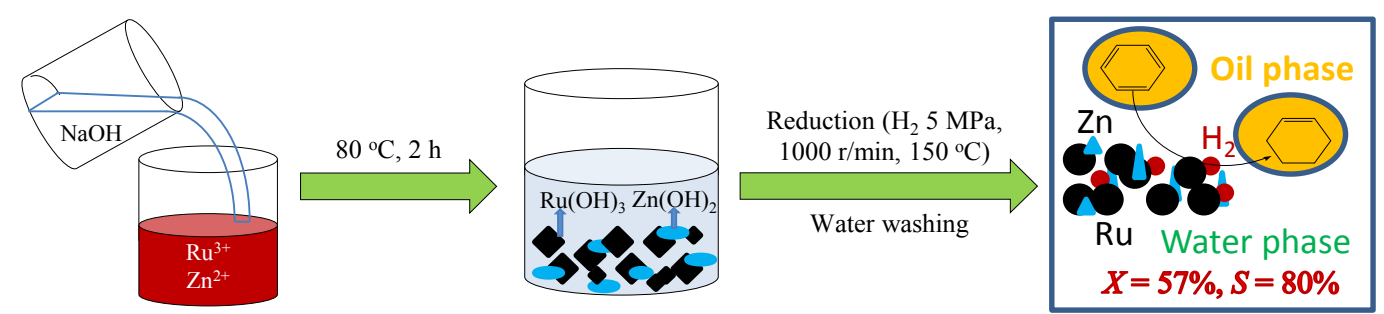

The Ru-Zn catalysts did not need to be washed after the coprecipitation and could just be washed with water (decantation) after the reduction. The Ru-Zn catalysts with a $\mathrm{ZnO}$ crystal phase showed high catalytic performance in the selective hydrogenation of benzene.

M S, Liu Z Y. Chem Eng J, 2013, 218: 415

[22] Sun H J, Wang H X, Jiang H B, Li S H, Liu S C, Liu Z Y, Yuan X M, Yang K J. Appl Catal A, 2013, 450: 160

[23] Sun H J, Pan Y J, Jiang H B, Li S H, Zhang Y X, Liu S C, Liu Z Y. Appl Catal A, 2013, 464-465: 1

[24] Sun H J, Jiang H B, Li S H, Wang H X, Pan Y J, Dong Y Y, Liu S C, Liu Z Y. Chin J Catal (孙海杰, 江厚兵, 李帅辉, 王红霞, 潘雅洁, 董英英, 刘寿长, 刘仲毅. 催化学报), 2013, 34: 684

[25] Wang J Q, Wang Y Z, Xie S H, Qiao M H, Li H X, Fan K N. Appl Catal A, 2004, 272: 29

[26] Liu S C, Liu Z Y, Wang Z, Wu Y M, Yuan P. Chem Eng J, 2008, 139: 157

[27] Zhao Y J, Zhou J, Zhang J G, Wang S D. J Mol Catal A, 2009, 309: 35

[28] Liu J L, Zhu L J, Pei Y, Zhuang J H, Li H, Li H X, Qiao M H, Fan K N.
Appl Catal A, 2009, 353: 282

[29] Wang W T, Liu H Z, Wu T B, Zhang P, Ding G D, Liang S G, Jiang T, Han B X.J Mol Catal A, 2012, 355: 174

[30] Zhou G B, Tan X H, Pei Y, Fan K N, Qiao M H, Sun B, Zong B N. ChemCatChem, 2013, 5: 2425

[31] Zhang P, Wu T B, Jiang T, Wang W T, Liu H Z, Fan H L, Zhang Z F, Han B X. Green Chem, 2013, 15: 152

[32] Sun H J, Li S H, Zhang Y X, Jiang H B, Qu L L, Liu S C, Liu Z Y. Chin J Catal (孙海杰, 李帅辉, 张元馨, 江厚兵, 曲良龙, 刘寿长, 刘仲毅. 催化学报), 2013, 34: 1482

[33] Wang M H, Su H J, Zhou J, Wang S D. Chin J Catal (王铭浩, 苏宏久, 周谨, 王树东. 催化学报), 2013, 34: 1543

[34] Liu S C, Liu Z Y, Luo G, Han M L. Petrochem Technol (刘寿长, 刘仲 毅, 罗鸽, 韩民乐. 石油化工), 2002, 31: 720

\section{低碱度共沉淀法制备苯选择加氢Ru-Zn催化剂}

\author{
王正宝", 张 琪, 路晓飞, 陈双佳, 刘春杰 \\ 浙江大学化学工程与生物工程学院, 浙江杭州 310027
}

\begin{abstract}
摘要: 在低碱度下采用共沉淀法成功制备了非负载型Ru-Zn催化剂, 用于苯选择加氢制环己烯反应. 固定氢氧化钠沉淀剂的量, 考察了不同氯化锌加入量对催化剂结构和催化性能的影响, 采用 $\mathrm{N}_{2}$ 吸附、X射线衍射和程序升温还原等手段对催化剂进行了表征. 同时考察了选用具有最佳锌含量的Ru-Zn催化剂时摚拌速度和硫酸锌添加剂等对催化反应性能的影响, 最后考察了催化剂多次使 用时的反应性能. 研究表明, $\mathrm{Zn}$ 含量 $16.7 \%$ (质量分数)的 $\mathrm{Ru}-\mathrm{Zn}$ 催化剂具有最佳的催化性能; 在 $\mathrm{ZnSO}_{4}$ 水溶液 $(0.45 \mathrm{~mol} / \mathrm{L}$ )中, 优化 反应条件(哈氏合金釜, $1200 \mathrm{r} / \mathrm{min}, 150^{\circ} \mathrm{C}, \mathrm{H}_{2}$ 压 $5 \mathrm{MPa}$ )下反应 $45 \mathrm{~min}$, 苯转化率 $57 \%$ 时环已烯选择性可达 $80 \%$ (收率超过 $45 \%$ ). 钉 催化剂中 $\mathrm{ZnO}$ 晶体对于环已烯选择性达到 $80 \%$ 非常重要. 催化剂回收循环反应 5 次时反应性能基本不变, 表明低碱度下制备的催 化剂具有良好的稳定性, 显示了工业化应用前景.
\end{abstract}

关键词: 共沉淀法; 低碱度; 苯; 选择加氢; 钓锌催化剂

收稿日期: 2014-08-22. 接受日期: 2014-09-24. 出版日期: 2015-03-20.

*通讯联系人. 电话: (0571)87952391; 传真: (0571)87951227; 电子信箱: zbwang@zju.edu.cn

基金来源：国家自然科学基金(U1162129).

本文的英文电子版由Elsevier出版社在ScienceDirect上出版(http://www.sciencedirect.com/science/journal/18722067). 